\title{
Melancolia e modo de funcionamento dos melancólicos
}

\author{
Melancholy and operating mode of melancholics \\ Melancolía y modo del funcionamiento de los melancólicos \\ Ilka Franco Ferrari ${ }^{1}$ \\ Pontificia Universidade Católica de Minas Gerais
}

Breno Ferreira Pena

\begin{abstract}
Resumo
O texto aborda a melancolia como uma psicose e localiza os motivos para ponderá-la nessa posição subjetiva. São considerados pontos cruciais do modo de funcionamento desse tipo clínico de psicose, a dor de existir, a atuação peculiar do supereu, a autodepreciação e a culpabilidade que lhe são característicos e dizem de um modo específico de gozo que marca o corpo e o pensamento desses sujeitos. Freud, Lacan e autores contemporâneos, orientados por essa vertente teórica e prática, são os fios condutores da lógica tecida pelo texto e pelo caminho onde se encontra o ensinamento desses sujeitos sobre o supereu e uma culpabilidade típica, denunciando que a culpa não provém do pai.

Palavras-chave: melancolia; psicose; dor de existir; culpabilidade; budismo.
\end{abstract}

\begin{abstract}
The current research proposes the melancholy as a psychosis and investigates the causes to include it in its subjective role. The text considers crucial points in the way of how this kind of clinic psychosis works: existing pain, the special manner that the superego acts, the self-deprecation and the culpability - which are typical and say in a specific mode-of-jouissance which marks the person's body and thinking. Freud, Lancan and contemporary author's works that are geared to this theoretical and practices lines of approach are the main trusts of this work and where the lesson to be learned is about the superego and the typical culpability, taking off the father's guilty.

Keywords: melancholy; psychosis; existing pain; guilt; buddhism.
\end{abstract}

\begin{abstract}
Resumen
El texto aborda la melancolía como una psicosis y localiza los motivos para reflexionar acerca de ella desde esa posición subjetiva. En él son considerados puntos cruciales del modo de funcionamiento de éste tipo clínico de psicosis, el dolor de existir, la actuación peculiar del superyó, la autodepreciación y la culpabilidad que le son característicos y dicen de un modo específico de goce que marca el cuerpo y el pensamiento de estos sujetos. Freud, Lacan y autores contemporáneos orientados en esta vertiente teórica y práctica son los hilos conductores de la lógica tejida por el texto y por el camino donde se encuentra la enseñanza de estos sujetos acerca del superyó y una culpabilidad típica que denuncia que la culpa no proviene del padre.

Palabras clave: melancolía; psicosis; dolor de existir; culpabilidad; budismo.
\end{abstract}

\section{Introdução}

Abordar a melancolia, considerando-a um tipo clínico da psicose, com base no que Freud e Lacan ensinaram, inequivocamente é retirá-la do embaraço onde se localizam o transtorno bipolar descrito em sistemas classificatórios atuais, as depressões e tristezas generalizadas.

Em grego, o termo melancolia significa bile negra e se adequou bem às ideias hipocráticas de uma bile que afetava, de forma nefasta, o cérebro humano. Freud, interessado no tema, não ignorou os conhecimentos produzidos, as questões próprias de cada época, mas tomou rumo próprio.

Freud transitava pelo campo da produção psiquiátrica sobre o assunto, em meio à fertilidade

1 Endereço: Programa de Pós-graduação em Psicologia da PUC Minas. Avenida Itaú, 525, Prédio Redentoristas, Bairro Dom Cabral. Belo Horizonte-MG. CEP: 30535-012. de ideias de autores como Philippe Pinel (17451826), Jean-Etienne Esquirol (1772-1840), Joseph Guislain (1797-1860), Wilhelm Griesinger (18171868), Jules Baillarger (1809-1890), Jules Falret (1824-1902), Emil Kraepelin (1856-1926), Jules Séglas (1856-1939), Jules Cotard (1840-1889), que frutificavam polêmicas envolvendo a nosologia da melancolia nos séculos XIX e XX. Mas, por sua vez, como bem escreve Quinet (1997), não se deteve nas querelas e, de forma original, situou a melancolia como um tipo especial de depressão, supondo-a uma dinâmica subjetiva específica. Ele soube aproveitar conhecimentos existentes.

Séglas, seguindo o que informa Quinet (1997), parece ser seu ponto de apoio para colocar a melancolia em série com a esquizofrenia, naquilo que esse autor desenvolveu sobre o que chamou de fenômenos elementares constituintes da melancolia, em 1894. Dor moral, distúrbios cenestésicos e intelectivos compõem esses fenômenos a partir dos quais o delírio 
pode sobrevir, secundariamente. Os distúrbios do corpo e do pensamento estão na origem da dor moral, sintoma que traduz toda gama de paixões tristes e leva ao afastamento do mundo.

Atacar sua própria imagem, a bem da verdade, é uma das peculiaridades da relação do melancólico com seu corpo. Lacan favorece essa compreensão nos últimos capítulos do "Seminário: a angústia" (1962-1963/2005), momento em que se refere ao luto de Hamlet. Para ele, atacar o próprio corpo é uma tentativa, ainda que fracassada, que o melancólico encontra para fazer a extração do objeto $a$, objeto ao qual se encontra identificado em sua condição de objeto dejeto, ou seja, sem a mediação da significação fálica. E o ato suicida, muito típico nesses casos, desvela a tentativa de separação radical do Outro, na falta de se separar da identificação a esse objeto dejeto. Séglas já informava à comunidade científica de sua época que a tentativa de suicídio dos melancólicos era uma forma de retirar do mundo o ser incapaz, inútil, ou seja, dejeto.

A experiência psicanalítica favoreceu, aos estudiosos e interessados na prática, a comprovação de que não se nasce com um corpo, a comprovação de que o corpo não é um dado primário, já que o vivente jamais é idêntico ao corpo. Ela ensinou que, para a existência de um corpo como experiência subjetiva, é necessária a intervenção da imagem corporal que se agrega ao organismo do vivente, imagem que o simbólico dá significado. Isso quer dizer que, para a constituição do corpo imaginário, é necessária a intervenção do corpo simbólico que deve ser incorporado. Na psicose, isso não é possível, e o corpo se torna lugar de gozo não limitado pela operação simbólica.

Lacan, em “Televisão" (1973/2003, p. 524), mais uma vez, menciona as questões sobre os melancólicos. Ele foi um estudioso que não se deteve muito no tema da melancolia, mas do pouco que escreveu muito se pode extrair. Manteve a melancolia como psicose e, se falava da depressão de modo geral como "simplesmente uma falha [faute] moral, como se exprimiam Dante ou até Espinosa", como "um pecado, o que significa uma covardia moral, que só é situado, em última instância, a partir do pensamento, isto é, do dever do bem dizer, ou se referenciar no inconsciente", para a melancolia recorreu ao budismo e disse da dor de existir em estado puro, particularizando uma dor própria de todo humano.

As elaborações lacanianas sobre o supereu favoreceram a compreensão da melancólica como uma forma de psicose. Para Lacan, que considerava a estrutura como a estrutura da linguagem, a matriz do supereu só podia estar presente a partir da existência da voz do Outro primordial. E, assim sendo, os melancólicos, fora do registro do Nome-do-pai, constituem o melhor exemplo de que a culpabilidade não provém do pai.

\section{Neurose narcísica, psicose}

O estudioso atento observa que Freud não deixou caso algum que seja paradigmático de melancolia, a exemplo do que ele construiu para a histeria, neurose obsessiva, fobia e paranoia. Mas tampouco lhe resulta difícil constatar que Freud a coloca no campo das neuroses narcísicas, tal como observa Bogochvol (2008). Uma neurose narcísica marcada por uma perda de objeto que resulta em efeitos específicos sobre o eu, ou seja, em processo diferente do que ocorreria se houvesse o recalque.

Ao tecer considerações sobre o eu ideal i $(a)$ e ideal do eu $\mathrm{I}(a)$ que estão diretamente implicados na organização da subjetividade e do campo da realidade, Bogochvol (2008), psicanalista de orientação lacaniana, é bem preciso ao dizer que, ao ocorrer a perda do objeto, esburacando o Outro, o abalo no funcionamento psíquico e nas relações com o mundo também ocorre. E a melancolia é uma das formas possíveis de resposta a esse abalo. Nela "não existe um i $(a)$ sustentado pela função fálica da castração, e a perda do objeto faz o sujeito se deparar com a foraclusão $\varphi$ " (Bogochvol, 2008, p. 200). Para o melancólico, nesse momento, o que se apresenta da forma arcaica e radical é o objeto $a$ desvelado, sem nenhum recobrimento do imaginário:

$\mathrm{O}$ que distingue o que é próprio do ciclo maniamelancolia de tudo o que caracteriza o ciclo ideal da referência ao luto e ao desejo, só podemos apreendêlo ao acentuar a diferença de função entre, por um lado, a relação de a com i(a) no luto e, por outro, no outro ciclo, a referência radical ao a, mais arraigada para o sujeito que qualquer outra relação, mas também intrinsecamente desconhecida, alienada, na relação narcísica (Lacan, 1962-1963/2005, p. 364).

Essa foraclusão própria da melancolia diz da ausência de $\mathrm{I}(a)$ na organização da rede significante, das significações. O melancólico não consegue constituir um eu ideal articulado ao ideal do eu, como os neuróticos o fazem, porque nele, pura e simplesmente, o ideal do eu não existe, o que consequentemente estabelece um modo de gozo específico. Assim é que, pelo furo aberto no psiquismo, a libido se esvai como em uma hemorragia, diz Bogochvol (2008), recordando Freud. E, nesse caso, do que se trata então é de um vazio e não da falta, resultando na fenomenologia melancólica onde chamam a atenção a dor de existir, a autodepreciação ou diminuição significativa da autoestima, e a culpabilidade.

Fenomenologia bem descrita por Freud, que localiza sua origem na identificação do sujeito melancólico com o objeto perdido. Quando a perda de objeto acontece, a libido liberada é revertida para o eu, nesse caso o eu ( $m o i)$, promovendo a identificação com o objeto abandonado, dando-lhe certeza sobre seu ser. $\mathrm{O}$ eu perde suas vestes narcísicas, consequentemente $\mathrm{o}$ interesse pelo mundo exterior e o amor próprio, o 
que pode ser visto, por exemplo, nas autoacusações e culpabilidade.

A questão essencial que gira em torno da identificação melancólica, portanto, é o fato de que a perda de um objeto faz com que o sujeito se identifique maciçamente a ele. O melancólico, como frisa Freud em "Luto e melancolia" (1915/1996), não sabe o que perdeu. Dessa forma, ele não pode reintegrar os traços identificatórios desse objeto, identificando-se, então, ao objeto em si. A morte do objeto perdido é vivida, portanto, no eu. Ao rejeitar a perda, introduzindo o objeto em seu eu, acaba sendo consumido por esse objeto que triunfa no processo (Lacan, 1962-1963/2005).

Nessas circunstâncias, o eu é julgado pelo supereu que acusa o sujeito, supereu que conta com a pulsão de morte não moderada como na neurose, estrutura em que uma parte dessa pulsão se encontra mesclada aos componentes eróticos e outra, aos agressivos. E, por meio desse processo, pode-se lançar luz sobre o que Freud dizia a respeito do empobrecimento do eu na melancolia e da mortificação melancólica mencionada por Lacan.

A culpabilidade, como lembra Vicente (1993), está diretamente associada à tentativa que o melancólico faz para subjetivar a perda, chegando até mesmo ao delírio de infâmia e inferioridade. Ela também é relativa à certeza que o melancólico tem sobre seu ser, identificado ao objeto abandonado: ele é um dejeto. Exatamente por faltar-lhe a mediação simbólica da perda, feita pelo Nome-do-pai, o melancólico é arremessado ao puro real do objeto: "Com efeito, tratase de um objeto que é um puro resto, na medida em que não foi alvo da operação de extração promovida pela função significante" (Santiago, 2009, p. 50).

O objeto $a$ com estatuto de rebotalho do simbólico desfaz a conjunção do imaginário e real, constitutivas de i(a), ou seja, quando o sujeito depara a foraclusão do Nome-do-pai, o objeto se apresenta somente no real: "No momento que o sujeito se depara com a foraclusão do Nome-do-pai, há uma perda das vestes narcísicas do objeto: a imagem cai e o sujeito se vê identificado com o objeto" (Quinet, 2006, p. 210).

O objeto $a$, nesse caso, não se faz presente como causa de desejo, mas, como ressalta Lacan (19621963/2005), como objeto causa de tormentos. Nesse momento, o melancólico se coloca como dejeto do Outro, entregue às ações do supereu, o que o faz submergir em uma dor muito intensa, já observada pela psiquiatria clássica, e que Lacan trabalhou como a dor de existir em seu estado puro, inspirando-se nas práticas de salvação do budismo.

\section{Do budismo à dor de existir em estado puro}

É conhecido que Lacan deixou duas importantes passagens que orientam reflexões sobre a melancolia estruturada como psicose. Uma delas se encontra no Seminário “A ética” (1959-1960/1988), e a outra na Lição XXV do Seminário "A angústia” (19621963/2005). Delas resulta o sujeito melancólico que sacrifica o simbólico, morto-vivo que quer ser ninguém, na falta de ser ninguém típica da função fálica (Ferrari, 2006).

Morto-vivo em busca de uma segunda morte é modo lacaniano de dizer, inspirado em Sófocles e sua Antígona. Nesse caso, o melancólico é o condenado que tenta encontrar uma segunda morte que o retire do isolamento em que se encontra decorrente da reversão da libido objetal sobre o eu (moi). E, ademais, de seu acometimento da dor de existir em sua forma pura. Se a dor de existir é condição humana, esses sujeitos a vivem puramente.

Em "Observação sobre o relatório de Daniel Lagache" (1958-1960/1998b) e "Kant com Sade" (1963/1998a) pode-se ver Lacan abordando a dor de existir inerente à condição humana e aquela própria da melancolia.

Do importante texto "Observação sobre o relatório de Daniel Lagache" interessa aqui extrair, entre outros dados, Lacan ensinando que existir não é viver. Viver supõe o existir recoberto pelo Outro. Existir está na dimensão de ser lançado no mundo com a dor que isso comporta; mundo em que a linguagem não dá conta de todos os juízos. Ela até dá conta do juízo de atribuição, mas falha no que respeita ao juízo de existência, já que a existência, por si, é foracluída do Outro.

Em "Kant com Sade" (1963/1998a, p. 788), quando critica certos psiquiatras que desconsideravam a dor de existir como evidência original nas práticas de salvação budista, Lacan diz: "Pois então não ouviram eles, se creem ter um ouvido melhor do que os outros psiquiatras, essa dor em estado puro modelar a canção de alguns doentes, denominados melancólicos?". Assim, a dor de existir em seu estado puro aparece pela primeira vez. Logo a seguir, ainda pergunta: "Nem colheram um daqueles sonhos em que o sonhador fica transtornado, por ter, na condição sentida de um renascimento inesgotável, estado no âmago da dor de existir?".

Freud esteve desde o princípio da psicanálise às voltas com a dor psíquica, como se pode ver em sua correspondência com Fliess, tal como bem escreve Quinet (2006). E com ele se pode apreender que ela é sempre vinculada à castração à qual, a cada perda, o sujeito é remetido e é sempre relativa à emergência de excesso de gozo rompendo a barreira do simbólico. Para Freud, tanto no luto quanto na melancolia, o que está na base é a perda do que escamoteava a castração. Nas palavras de Quinet (2006, p. 173), no neurótico, "a castração se inscreve como falta de um significante que complete o Outro, evocando a negativização do falo imaginário $(-\varphi)$ ", e, na psicose, como há "falta da inscrição simbólica da castração, essa falta se manifesta como furo real correlativo à elisão do falo 
$(\Phi 0) "$

Na neurose, há um menos de gozo, negativização que a linguagem introduz levando a certa renúncia de gozo. Mas, nela, ele é compensado por um mais de gozar: se há uma falta, um objeto pode vir a preenchê-la. Conforme ensina Vicente (1993), citando o seminário de Colette Soler ocorrido em 1988-1989, na melancolia, o menos de gozo decorrente da negatividade essencial que a linguagem introduz se torna absoluto, não funciona no modo de complementaridade com um mais de gozar, já que o articulador dos polos negativização/positivação é o falo. Nela eles se encontram dissociados.

O psicanalista La Sagna, em conferência pronunciada na cidade de Belo Horizonte, enfatiza que a dor de existir que Lacan aborda a propósito da melancolia é difícil de imaginar, porque anterior ao significante, é inconstituída, não subjetivável. Tratase de um afeto do corpo que se recusa à forma, ao símbolo, e tem relação íntima com a inibição: "É um corpo despedaçado, mas anterior ao signo, e, no fundo, é isso que Lacan designa como a dor de existir. É algo que não é verdadeiramente subjetivável" (La Sagna, 2010, p. 34). Reafirma que Lacan retirou essa expressão do budismo primitivo, que precede Buda, daquilo que chamavam de átima para se referirem a um ser simples, estranho a qualquer representação e multiplicidade.

Átima, por se colocar a pensar, cria o mundo, segue La Sagna. Cria o múltiplo que será, assim, o mundo da dor, pois, neste mundo que contém o múltiplo inexoravelmente, algo sempre lhe faltará, faltará o um. O mundo sofre pela perda do um, pelo vazio de qualquer princípio pessoal, ausência de um si mesmo do qual ninguém escapa, e a dor do melancólico se junta a essa dor. O melancólico incessantemente reencontra a dor do mundo na dor de existir, em uma espécie de renascimento constante, ao acordar todas as manhãs e ter o sentimento de que tudo vai realmente muito mal.

No budismo, a dor só cessa quando é possível atingir o estado de nirvana, estado de desapego, de aniquilação do eu, que possibilita a iluminação e pode retirar o humano dos vícios e das paixões que se originam da cobiça, do ódio e também do erro (Novak e Smith, 2008). Para que ela cesse, é necessário apagar o desejo de objetos do mundo, um desejo pelo múltiplo, que traz como consequência a paixão conhecida como ignorância, a recusa do saber, um estado de não querer saber nada disso, conforme assegura La Sagna (2010). Mas, nesse ponto, a psicanálise toma rumo distinto: a saída da dor de existir não está na abolição do desejo, já que isso leva mesmo é ao culto da pulsão de morte, e os melancólicos ensinam sobre, já que no apagamento do desejo, têm a morte como tema frequente. Para a psicanálise, a saída se encontra no desejo de saber (Quinet 2006).

De acordo com o que lembra esse autor (2006, p. 174), o nirvana budista, estado equivalente a um retorno ao inanimado, o que faz mesmo é desvelar a dor de existir, que é essencialmente gozo: "A dor de existir detectada pelo budismo é a que se encontra no para além do Édipo, outro nome do para além do princípio do prazer". Pode-se dizer, ainda, que ela se encontra em um aquém da própria vida, bem exemplificado por Sófocles em "Édipo em Colono", que bradou um “antes não ter nascido!" e da qual o melancólico dá testemunho. Lugar de gozo insuportável, em que o reinado cabe à pulsão de morte.

$\mathrm{Na}$ época em que Lacan escrevia "Kant com Sade", 1963, publicado originalmente na revista "Critique" (número 191, abril 1963), ocasião em que falou pela primeira vez da dor de existir em forma pura, como se escreveu anteriormente, ele ministrava também o Seminário, livro 10, “A angústia”, de 1962-1963. Nesse Seminário, o gozo é formulado para além da lógica fálica e, portanto, pode ser entendido como um modo de gozo mais puro ao ser disjunto de qualquer significante, mostrando-se impregnado pelo real: "É no Seminário 'A angústia' que o gozo se libera da amarração significante de sua prisão fálica e que nele se demonstra, ao contrário, que são os objetos a que dão corpo ao gozo" (Miller, 2005, p. 28).

A partir de sua concepção do supereu como objeto $a$, voz, vertente mais real do supereu no ensino lacaniano e bastante desenvolvida na década de 1960, como ressalta Miller (1986), Lacan pode trabalhar outra forma de gozo, aquela fora da lógica do significante. E essa forma de gozar, sem referência fálica, caracteriza o funcionamento do psicótico e favorece a concepção da dor do melancólico.

La Sagna (2010) também chama atenção para a forma de gozo própria da melancolia, ao dizer que os melancólicos sabem algo que os outros não sabem no que diz respeito ao gozo e, assim, são impelidos por um não querer saber, já que não têm como reduzir o gozo ao semblante, como faz o neurótico.

No caso dos monges, ao que tudo indica, também há um contato com o gozo em sua vertente mais real, pois, como afirma Quinet (2006), o nirvana budista visa à dor estritamente vinculada a ela mesma, ao vazio do sujeito em um contato com a dor de existir em si. Assim, essas práticas de salvação, que visam a eliminar o apego, o desejo e até mesmo qualquer tipo de demanda para se chegar ao estado de nirvana supõem a aniquilação do eu, e, nesse momento, falta aos monges, além da consistência imaginária dada pelo eu, a referência fálica vinda com o simbólico. Isso porque o estado de nirvana pretende possibilitar aos monges o encontro com o puro real, dor de existir. E isso pode lhes favorecer, portanto, mesmo que neuróticos, o encontro com o gozo fora do simbólico, por meio de práticas que procuram colocar em evidência a dor de existir da forma mais pura. Por não ter o recobrimento do Outro, o melancólico entrega-se a um gozo avassalador, fora de qualquer 
mediação simbólica, que guarda aproximações com o dos monges budistas em estado de nirvana. Gozo real ou impossível que, ao ter este estatuto, como enfatiza Miller (2005), não pode ser descrito em palavras.

É interessante notar que essa impossibilidade de significar este tipo de gozo real, que existe no êxtase, é descrita também pelo próprio Buda, ao relatar sua experiência. Para ele, sempre foi impossível explicar com palavras o que lhe havia passado em seu estado de nirvana. Por isso considerava que esse estado deveria ser vivenciado por cada um, pois não haveria forma de transmitir a experiência, como frisa Levenson (2009).

\section{Triste tristeza e sua defesa maníaca}

Com base no exposto, evidencia-se que os melancólicos sofrem de uma tristeza muito triste e não uma tristeza qualquer. Sofrem de uma depressão profundamente dolorosa, tal como Freud escreve em "Luto e melancolia" (1915/1996), já que, lançados à condição de objeto dejeto, identificados ao que é largado pelo Outro, ao objeto $a$, refugiando-se no silêncio do afastamento do Outro do desejo e do inconsciente.

Nessa posição, eles se deixam comandar pelo supereu, que os pune sadicamente, e se afundam no gozo masoquista, na espera delirante de punição. $\mathrm{Na}$ dor que os alimenta, eles se consomem na pura cultura da pulsão de morte, tal como se expressou Freud.

Se o primário desse tipo clínico é a perda do objeto, do objeto do amor, simbólico, situado no ideal do eu, isso o levará secundariamente a uma perda da consistência imaginária de seu eu. Não se trata, assim, de uma regressão ao narcisismo como se costuma ouvir, mas de abalo do ideal do eu com consequente abalo no eu ideal, ferida narcísica.

$\mathrm{Na}$ dor de existir desses sujeitos, presencia-se a estrutura do Outro que é anulada, levando-os à negação de tudo que existe: seu corpo, seus órgãos, a morte, o mundo... Tal como o psiquiatra Cotard descreveu, em 1882, no que passou a ser conhecido como "delírio das negações" e também "síndrome de Cotard". Nessa síndrome, observam-se ideias de culpa, ruína e negação sistematizada. Não se trata da negação típica da neurose que nega afirmando e afirma negando, como a sistematizou Freud na "Verneinung" que supõe o recalque. Na melancolia, nega-se a própria existência daquilo que é negado, abolindo, zerando o que se nega. Diante de uma rosa, são capazes de dizer que aquilo não é uma rosa, não é uma flor, já não têm estômago, cabeça, etc., e, em alguns casos, ocorre a negação universal, ou seja, nada mais existe, nem eles mesmos. Não é sem sentido, então, que Freud dirá, no texto "O ego e o id", de 1923, que a melancolia é a pura cultura de morte.

Mas esses sujeitos têm seus artifícios para buscar uma forma de reconstituição desse Outro. E isso pode ser visto também em delírio que lhes é próprio, aquele em que há o Outro que pune por crime do qual o melancólico se autoacusa de forma devastadora. Séglas, como bem assinala Quinet (1997), já havia descrito com precisão a autodepreciação levando a vivências de resignação, vivências de que são merecedores do sofrimento e das desgraças pelas quais passavam, pois, se aquilo acontecia, diziam os pacientes, era devido às faltas por eles cometidas, e a justiça se fazia necessária. Daí Séglas não deixou de comparar o delírio do melancólico com o delírio de perseguição típico da paranoia: um centrífugo e o outro centrípeto.

Nessa comparação, o delírio melancólico supõe uma humildade em que o paciente acaba sendo o próprio mal, e o paranoico, o paciente orgulhoso que vê a nocividade fora de si. Em linguagem psicanalítica, a partir de Séglas, pode-se dizer que o melancólico é o próprio culpado de tudo, diferentemente do paranoico, para quem a culpa é do Outro. Pode-se afirmar que o melancólico vai em direção à construção de delírio de pequenez, pois o eu ataca sua própria imagem, fazendo-o rebotalho do Outro, e o paranoico inventa delírio de grandeza, em sua posição de objeto maisde-gozo do Outro, já que é um perseguido do Outro. Ambos, entretanto, situados como objetos do Outro.

A autoacusação melancólica, dessa forma, revela a manifestação da pulsão de morte no supereu, outro que acusa, já que o sujeito identificado ao objeto atrai a ferocidade do supereu. Assim é que a psicanálise lacaniana chegou ao ponto de concluir que a mania é a forma que o melancólico encontra para se defender dessa tirania. Mania como tentativa de se agarrar ao imaginário, a um ideal.

Freud (1915/1996, p. 259), em sua época, dizia que a característica mais notável da melancolia, aquela necessitada de explicação, é essa sua tendência em se transformar em mania, estado que é oposto do ponto de vista sintomático, ainda que isso não acontecesse em todos os casos. Observa que "vários investigadores psicanalíticos" já haviam colocado em palavras o fato do conteúdo da mania não diferir em nada do conteúdo da melancolia. Isso porque ambas lidam "com o mesmo "complexo", mas provavelmente, na melancolia, o ego sucumbe ao complexo, ao passo que, na mania, domina-o ou o põe de lado. Triunfa sobre ele. Lacan fez outras considerações sobre esse tema.

Para Lacan (1962-1963/2005), no caso da mania, o que se nota é que o sujeito, ao não estar enlaçado por objeto $a$ algum, vê-se entregue, sem nenhuma possibilidade de liberdade, a uma metonímia infinita e lúdica da cadeia significante. De acordo com Álvarez, Esteban e Sauvagnat (2004, p. 205), essa concepção lacaniana só pode ser bem entendida quando situada na tradição das investigações sobre fuga de ideias, especialmente elaboradas por Liepmann e Hönigswald. Esses autores, desde o início do século 
XX, buscaram "determinar a natureza do mecanismo pelo qual o sujeito normal chega a rechaçar de seu discurso ou sucessão de ideias as associações indesejáveis". O que pode ser entendido na expressão lacaniana de que os psicóticos estão fora do discurso.

Ao desvelar a estrutura autista da pulsão, já que o sujeito é seu objeto, os sujeitos melancólicos, desde Freud, convocam aos psicanalistas para intenso trabalho que favoreça a direção de tratamento. Ao ensinarem que a ausência da inscrição do falo no inconsciente, significante da vida e da diferença sexual, impede a negativização do gozo na psicose, também ensinam que cada qual tem que inventar recursos, solução particular para lidar com a satisfação mortífera da pulsão. Nesse modo específico de funcionamento, é importante que o tratamento favoreça construções, de forma única, frente ao gozo avassalador que pode invadir esses sujeitos no cotidiano da vida. Mas é importante dizer que se trata de modo de funcionamento que ainda interroga aos analistas sobre a dificuldade do cumprimento do dever ético do bem-dizer, própria dos melancólicos.

\section{Referências}

Álvarez, J. M., Esteban, R., Sauvagnat, F. (2004). Fundamentos de psicopatologia psicoanalítica. Madrid: Sintesis.

Bogochvol, A. (2008). Melancolia. In: Scilicet: os objetos a na experiência analítica. (pp. 199-203). Rio de Janeiro: Contra Capa.

Ferrari, I. F. (2006). Melancolia: de Freud a Lacan, a dor de existir. In: Revista latino-americana de psicopatologia fundamental, 6, 105-115.

Freud, S. (1996). Luto e melancolia. In: Psicologia das massas e análise do ego. In: Edição standard das obras completas de Sigmund Freud. (Jayme Salomão, trad., v. 19, pp. 249-263). Rio de Janeiro: Imago. (Trabalho original publicado em 1915)
Freud, Sigmund. (1996). O ego e o id. In: Edição standard das obras completas de Sigmund Freud. (Jayme Salomão, trad., v. 19, pp. 27-71). Rio de Janeiro: Imago. (Trabalho original publicado em 1923)

Lacan, J. (1998a). Kant com Sade. In: Escritos. (pp. 776-803). Rio de Janeiro: Jorge Zahar. (Trabalho original publicado em 1963)

Lacan, J. (1998b). Observação sobre o relatório de Daniel Lagache: "Psicanálise e estrutura da personalidade". In: Escritos. (pp. 653-691). Rio de Janeiro: Jorge Zahar. (Trabalho original publicado em 1958-1960)

Lacan, J. (1988). O seminário, livro 7: a ética da psicanálise. Rio de Janeiro: Jorge Zahar. (Trabalho original publicado em 19591960)

Lacan, J. (2005). O seminário, livro 10:_a angústia. Rio de Janeiro: Jorge Zahar. (Trabalho original publicado em 1962-1963)

Lacan, J. (1973). Televisão. In: Outros escritos. (pp. 508-543). Rio de Janeiro: Jorge Zahar. (Trabalho original publicado em 1973)

La Sagna, P. (2010). A alegria de viver. In: Revista Curinga, $30,27-51$.

Levenson, C. B. (2009). Budismo. Porto Alegre: L\&PM.

Miller, J. A. (1986). A clínica do supereu. In: $\underline{\text { Recorrido de }}$ Lacan. (pp. 131-148). Buenos Aires: Manantial.

Miller, J. A. (2005). Introdução à leitura do seminário $10 \mathrm{da}$ angústia de Jaques Lacan. In: Opção Lacaniana: Revista Brasileira Internacional de Psicanálise, 43, 7-91.

Novak, P. \& Smith, H. (2008). Budismo: uma introdução concisa. São Paulo: Pensamento-Cultrix.

Quinet, A. (1997). A melancolia nos clássicos. In: Teoria e clínica da Psicose. (pp.139-152). Rio de Janeiro: Forense Universitária.

Quinet, A. (2006). Psicose e laço social: esquizofrenia, paranoia e melancolia. Rio de Janeiro: Jorge Zahar.

Santiago, J. (2009). A dor de existir melancólica. Revista Curinga, 29, 45-52.

Vicente, V. (1993). Clínica diferencial de a melancolia y de la histeria. In: Freudiana, 9, 113-118.

Recebido: 15/12/2011

Última Revisão: 18/04/2012 Aceite Final: 11/05/2012

Sobre os autores:

Ilka Franco Ferrari - Doutora em Psicologia pela Universidade de Barcelona, coordenadora da Pós-graduação em Psicologia da PUC Minas, membro da Câmara de Pós-graduação do Conselho de Ensino e Pesquisa da PUC Minas, membro da Câmara do Departamento de Psicologia, membro do Conselho da Faculdade de Psicologia, membro da Escola Brasileira de Psicanálise - Seção Minas Gerais e da Associação Mundial de Psicanálise, editora responsável pela revista Psicologia em Revista. E-mail: francoferrari@terra.com.br; ilka@pucminas.br. Breno Ferreira Pena - Mestre em Psicologia pela Pontifícia Universidade Católica de Minas Gerais Psicólogo, especialista em Gestão de Pessoas pela Fundação Getúlio Vargas, psicanalista membro do Círculo Psicanalítico de Minas Gerais, psicólogo. 